\title{
Distribution analysis of argumentation frames in the text of court decision: Comparative analysis of law and sports science
}

\author{
LARISA LUTSKOVSKAIA \\ Department of Foreign Languages, Institute of Law, Peoples' Friendship University of Russia - RUDN University, \\ Moscow, Russian Federation
}

\begin{abstract}
The article focuses on comparative analysis of argumentative frames' distribution in the text of appeal court decisions pertaining to different law systems: US court opinions and Russian appellate rulings. Text of court decision is a communicative product of the judicial discourse which is argumentative by virtue of its nature; however, the sequence of frames implementing the argumentative discourse dynamics is specific to each type of court decision generated within respective law system. The present article explores the applicability of frame analysis to judicial argumentation in appeal court decisions pertaining to different law systems. The current interest of the research lays in the fact that court decision texts represent a relatively regular sequence of cognitive argumentation frames that provide for argumentative discourse dynamics, and that can be viewed as a cognitive tool of developing judge's argumentation strategy. The article aims at conducting an experiment on distribution analysis of the identified argumentation frames in the specified category of court decision texts and compare the traced regularities. The research methodology rests on application of the following methods: distribution analysis method, method of statistical analysis, methods of functional and structural analysis. The materials for the research included 50 texts including court opinions made by United States Court of Appeal for the seventh and ninth circuits and appellate rulings of Altay Regional Court (appeal instance). All documents carried the same type of the decision - affirming the lower court decision - and referred to criminal law only to preclude possible dependence of the research results on type of decision and branch of law concerned. In the research findings we came to the conclusion that within the chosen category of cases argumentation frames' distribution patterns exhibited insignificant variability however they were not absolutely rigid. The research outcomes can find further application for argumentation structure analysis in other categories of court decisions or other genres of the judicial discourse.
\end{abstract}

Keywords: Argumentation frame; Sports science; Court decision; Distribution pattern; Argumentation discourse.

Cite this article as:

Lutskovskaia, L. (2021). Distribution analysis of argumentation frames in the text of court decision: Comparative analysis of law and sports science. Journal of Human Sport and Exercise, 16(3proc), S1308-S1322. https://doi.org/10.14198/jhse.2021.16.Proc3.46

Corresponding author. Department of Foreign Languages, Institute of Law, Peoples' Friendship University of Russia - RUDN University, Moscow, Russian Federation.

E-mail: laravas@list.ru

Abstract submitted to: Winter Conferences of Sports Science. Costa Blanca Sports Science Events, 22-23 March 2021. Alicante, Spain.

JOURNAL OF HUMAN SPORT \& EXERCISE ISSN 1988-5202.

(c) Faculty of Education. University of Alicante.

doi:10.14198/jhse.2021.16.Proc3.46 


\section{INTRODUCTION}

Legal natural language argumentation is a complicated phenomenon that has been in the focus of research - both lawyers and linguists - for at least three decades. Texts of court decisions generated within various law systems can be regarded as fixed product of the judicial discourse which is inherently argumentative. Texts of court decisions are of considerable social significance due to the effect they have for a particular person concerned and for the society at large since one of their pragmatic functions is deterrence from socially condemned behaviour. From this perspective the argumentation structuring used in this type of texts has to be highly convincing. The author of a court decision text faces two-fold task: firstly, it must be ensured that the text itself is readable and comprehensible to public at large; secondly, the court decisions are to be well reasoned and based on explicit as well as logical argumentation. Within various law systems different argumentative patterns have been formed in a strive to develop effective linguistic argumentation mechanisms that would minimize the risk of ambiguity and uncertainty, and thus enhance public credit to the judicial system through transparent as well as well-reasoned court decisions of whatever instance. The above factors stipulate the current interest of the research.

The article aims at identifying and comparing patterns of argumentative frames' sequence in the argumentative part of the US court opinion texts and Russian appellate ruling texts as a means of developing judge's argumentation strategy in specific judicial discourse. To achieve the aim a number of tasks should be solved:

- To review the relevant research literature to provide minimum sufficient theoretical background for the research;

- To describe the research methodology, which rests on distribution analysis of argumentative frames;

- To conduct an empirical experiment aimed at identifying the most common patterns of argumentative frames distribution in both category of texts;

- To analyse the results and identify promising areas of research results' application.

The authors chose for analysis court decisions of appeal instance as the argumentation on this level of the judicial procedure deals mostly with matters of law, the level of abstraction is higher in comparison to court decisions of the first instance which necessarily entails the use of other argumentative patterns; besides the argumentation in court decision on appeal has not been substantially researched so far.

\section{Literature review}

Legal argumentation as a complicated phenomenon at the confluence of law and linguistics has been a subject of extensive research from various angles and research perspectives. As the research literature review demonstrates, one of the most influential, although sometimes criticized, approaches to structural analysis of legal arguments was developed on the basis of S.E. Toulmin's (2003) model described in his book "The Use of argument". It can be referred to as procedural form of argumentation as it provides the description of sequence of steps in defending one's argument through the following argumentative functions: Claim, Data, Warrant, Qualifier Rebuttal. Other research undertaken in line with logical model highlighting various aspects of argumentation are discussed in the works of such scholars as H. Prakken (2002), R.P. Luoi (1998), T.F. Gordon (1994). E.T. Feteris (2017) conducted a comprehensive research (first published in 1999) on various theoretical approaches and paradigms that influenced the development of contemporary legal argumentation studies as interdisciplinary research field. In the research of E. Björling (2016) legal argumentation is analysed as a specific tool that combines the concrete (facts) with the abstract (legal norms) thus making law; legal argumentation is viewed not as a product of law, but as a law itself. From this perspective the scholar concludes that fact and argument is an inseparable entity (Björling, 2016). 
Texts of court opinions have also come into the focus of linguistic research from various perspectives: translation, stylistic, grammar, artificial intelligence, and of course, argumentation. Thus, there are research investigating the writing style of court opinions from quantitative analysis perspective (Carlson, Livermore \& Rockmore, 2016). Other research focus on specific types of court opinions, for example R. Hikle and M. Nelson (2017) embarked on linguistic analysis of dissent opinions. Since judicial discourse is argumentative by virtue of its very nature scholars investigate specificity of judicial argumentation from various perspectives (Szczyrbak, 2009; Szczyrbak, 2014; Feteris \& Kloosterhuis, 2009; Bubnova et al., 2018; Bayanova et al., 2019; Khairullina et al., 2020).

The number of contemporary research into natural language argumentation from cognitive perspective is rather limited and mostly relates to computational linguistics. We believe, however, that the cognitive model of discourse analysis developed by T.A. van Dijk $(1997,2006)$ remains relevant for legal discourse analysis. The present article largely applies the term "Frame" to identify constituent units of legal argumentation in line with linguistic tradition of developing its content characteristics for lingua-cognitive analysis (Ungerer \& Schmidt, 1996; Fillmore, 1988; Tannen, 1993).

\section{MATERIALS AND METHODS}

As V.K. Batia points out, the texts of court decision are characterized by a four-stage cognitive structure, including the case identification, facts description, reasoning, and actual opinion (Bhatia, 1998). Besides it is possible to identify the composite structure, i.e., the traditional division of the text into the functionalcomposite parts - introduction, main part, and conclusion. As the elements of these two structures do not always coincide, researchers tend to consider that the court decision genre structure is not of categorical, but rather of a logical nature, determined by the communicative situation.

Therefore, we took into account the importance of content-based integrated analysis of contemporary legal discourse (Atabekova \& Shoustikova, 2018; Avdeev et al., 2019).

Moreover, frame-based approach has been used. It should be mentioned that currently this approach is applied to consider the conceptual architecture of the legal texts on the whole (Prokofieva et al., 2018; Atabekova et al., 2019).

It should be mentioned that the court decision is targeted on a fairly extensive range of recipients, including people who do not belong to the professional community of lawyers. Therefore, the text must be clear and convincing in regard to prove / not proved factual aspects of the case, as well as in regard to the legal assessment.

The texts of court decisions are highly institutional, whereby their authors, i.e., judges, as representatives of a certain social institution, are limited in their verbal behaviour. One of the most important characteristics of court decision texts is their argumentative nature, as texts of this kind have certain intentional attitudes and are primarily aimed at justifying the decision.

From cognitive perspective, which we adopt in this article, argumentative discourse of appeal court decision text can be described in terms of argumentative frames. In our previous research (Chilingaryan \& Lutkovskaya, 2015) we identified and described the following frames on the basis of "dictum" and "modus" discourse functions:

1.Fact - classification of the fact. 
2.Presentation of the fact - classification of the fact.

3.Fact - conditions for the fact's existence.

4.Fact - competence of the fact's source.

5.Presentation of the fact - competence of the fact's source.

6.Fact - limits of verification.

7.Fact - the statement of a goal.

8.Fact - the presence / absence of the possibility of the existence of the fact.

As this article aims at conducting distribution analysis of argumentative frames in the text of court decisions, we will provide only necessary minimum linguistic background.

The dictum and modus functions are viewed by the authors as core or frame forming functions optionally supplemented by evaluative components. Since judicial discourse is an argumentative type of discourse by its nature, we assume that the identified discourse functions provide dynamics of the argumentative discourse.

These argumentative functions can be content-focused (dictum) and operational (modus); accordingly, the text of court opinion can be considered as the sequence of these functions gathered into regular clusters (frames) with the additional insertion of optional evaluation elements.

Cognitive linguistic analysis of argumentation in the appeal court decision texts makes it possible to determine a range of communicative meanings inherent to the judicial discourse, which are expressed in the appropriate modus functions forming meta category of modus in this type of discourse.

The function of this meta category is qualification of the communicative event (dictum) by synthesizing the objective (law-based) and subjective (the position of the court, the judge) components of the argumentative frame. This synthesis lays the ground for realization of specific for court decision texts category of evidence.

We believe that the discourse of the argumentative part of the court decision is realized through a series of argumentative frames. Distribution of frames in the text of court decision is determined by the conventions adopted in a particular legal system regarding drafting the judicial texts as well as by the argumentative strategy chosen by the judge - author of the text- within the scope of the mentioned conventions.

\section{Materials and procedure}

As the material for the research the authors used texts of court opinions of the US Court of Appeals for the Seventh and Ninth Circuits and texts of appellate rulings of Altay Regional Court (appeal instance). All the texts chosen for analysis were homogeneous in terms of branch of law: criminal law, but covered various crimes: drug dealing, armed bank robbery, possessing of firearms, fraudulent obtaining money. The authors dimed it expedient to limit the research area to court decision texts of one type pertaining to the same jurisdiction: criminal law, affirming the decision of the lower court. Such limitation on experiment were agreed on firstly, to preclude possible variations of argumentation frames patterns due to other conventions of structuring argumentation that may be common in other jurisdictions, and secondly to ensure homogeneous material in terms of argumentation outcome; the authors believe that different argumentation outcomes render it unavoidable for judges to employ different patterns of developing argumentation. However, the authors did not limit the research area to the decisions on one particular type of crimes to obtain the reliable data on regularity of discourse frames' sequence patterns. The total number of the analysed texts is 50 (25 opinion texts, 25 appellate ruling texts). 
In order to verify the obtained data, the authors asked two legal experts to analyse the texts in terms of their argumentation structure and identify possible patterns of argumentation frames sequence on the basis of the developed meta-language for argumentation analysis. Both experts were provided with a list of the identified argumentation frames and were explained the basic linguistic meaning of the meta-language proposed as a tool for analysis. The results of their evaluation were compared. To measure the agreement between two experts kappa measure was used which gave the result of $64 \%$ of agreement. The discrepancies in legal experts' evaluation were analysed, the majority of them were caused by different perception of arguments' boundaries in the texts.

\section{Experiment on frame distribution analysis}

In this part of the article, we will provide sample analysis of frame distribution regularities in two types of documents: US court opinion text and Russian appellate ruling text. The authors were interested in empirical verification of their hypothesis of applicability of the identified argumentative frames to the texts pertaining to the same genre of legal documents but from different legal systems. It should be clarified here that we understand of the term "distribution" in the sense of "sequence" and use this term to highlight the traced regularities of the argumentation frames patterns identified in the course of the experiment. The analysis also covers some linguistic means of argumentation frames' realisation in the discourse. To ensure the clarity of the experiment results authors selected for analysis texts with the same outcome: upholding the decision of the court of the first instance. It should also be mentioned that for ethical reasons authors used "XX" sign instead of real names in texts fragments cited as examples.

\section{Frames distribution analysis in us court opinion texts}

This section provides the example of frame distribution analysis applied to one of the court opinion texts taken from the corpus of the analysed texts (appeal No 07-3248). The argumentative part of a court opinion referred to as Discussion usually begins with a strong argument that sets the stage for further argumentative steps leading to conclusion; at the same time, it communicates the reader certain topical boundaries within which argumentation will be developed.

We review for clear error a district court's findings of fact regarding a defendant's level of participation in an offence. United States v. Olivas-Ramirez, 487 F.3d 512, 516 (7th Cir. 2007).

This text fragment opens the argumentative part of the analysed opinion text. Applying the developed metalanguage, it can be described as "fact - limits of verification" frame. Positioned in the very beginning of the argumentative part, the use of this frame is intended to specify the argumentative field of the entire document. This text position, along with the frame "Fact - limits of verification" can also be taken by "Presentation of the fact - classification of the fact" frame. Such use of the second frame is frequent enough and, apparently, is linked to the presentation of argumentation starting points of the appealing party; whereas the frame "Fact - limits of verification" sets out the court's argumentative position. It should be pointed out again that court opinion texts are written by one judge, however the text is drafted on behalf of the first person plural "We" thus highlighting the objectivity of the subsequent decision on the one hand and distributing the responsibility for it on all members of the panel, on the other.

"Limits of verification" frame is normally followed by the frame "Fact - conditions for the fact's existence". This pattern of sequence is not mandatory, but occurs rather frequently especially in appeals concerning judicial errors:

We will find clear error only when we are "left with a definite and firm conviction that a mistake has been committed". 
On the level of textual realization, the presence of focal marker "only" sets rigid time and conditional limits to the existence of the fact. The same meaning is emphasized by the citation used, which also serves as a specific way of expressing Modus function of high degree of confidence in judicial discourse. The use of assessment component indicating high degree of confidence is essential for constructing reliable argumentative strategy.

The use of this frame in most cases is associated with the use of a frame "fact - limits of verification" in the initial position, i.e., when argumentative strategy is structured from the court's perspective (We review.., we will find.....). The discourse function of this frame is to precise the general scope of verification identified in the before going text fragment and convey the discourse dynamics to the subsequent argumentative micro topics.

Further, the author of the analysed document resorts to the use of "Presentation of fact - classification of fact" frame, which more specifically defines the subsequent arguments, i.e., the specific facts are presented in respect of which the hearing on the appeal is held. It should be noted that the judge writing the opinion text introduces every new argumentation micro topic through the use of appellant's reported arguments.

On appeal, XX argues that the district court clearly erred when it denied him a downward adjustment under U.S.S.G.\$3B1.2(b) for his minor role in the offence. XX contends that his actions amounted only to joint occupancy of a stash house and participation in a single drug transaction at the direction of another.

It is possible to say that this frame specifies the following argument, on the grounds that it contains the appeal starting points of the convicted person, which are presented by the court, respectively, these points will serve as the starting point of judge's reasoning. These frames, along with "fact - limits of verification" frames are also frequently found at the beginning of the argumentative part of the court opinion; after this part the author (judge) moves on to considering in detail every point raised on appeal.

The Sentencing Guidelines allow a defendant's offence level to be reduced by two levels when the defendant is a "minor participant" in the offence. United States v. Emerson, 501 F.3d 804, 815 (7 $7^{\text {th }}$ Cir. 2007).

In this case, the author of document has resorted to the use of "conditions for the fact's existence" frame in constructing the argumentation. This choice, apparently, could be explained by author's reference to the Sentencing Guidelines, (the document, designed to help judges decide on an appropriate sentence and calculate the term of punishment), that provides downward sentence adjustment on the basis of establishing the fact of Defendant-Appellant's minor role in the offence. The function of this frame apparently is to maintain the argumentation flow through referral to existing extra linguistic legal realities.

After each argumentative micro topic, the author provides legal decision on the issue:

... we rejected a defendant's contention on appeal that he deserved a 4-level reduction and upheld the district court's decision to grant a 2-level reduction.

It is interesting to note, that the author uses the indefinite article (a defendant's contention), which serves the purpose of depersonification of the defendant-appellant, thus enhancing the objectivity of the rejection.

Next the author of the document moves to another argumentative micro topic, introduced with the frame "Presentation of the fact - competence of the fact's source ": 
XX also relies upon United States v. Hunte, 196 F.3d 687, 689 (7th Cir. 1999), in which we reversed the district court's denial of a motion for a section $3 B 1.2$ reduction. This case hardly controls the present situation.

The conducted analysis revealed that there is a tendency to introduce every new micro topic of argumentation through the use of frames containing the dictum function "presentation of the fact". Lexically this function is realized through the use of such performatives as: defendant's name argues, contends, disputes, insists, asserts, claims etc. It appears that criminal judges involved in writing court opinion texts mostly prefer to structure the argumentation by severing the identified field of argumentation into certain number of steps introduced as reported arguments and deal with each of them singly, at the same time remaining within the framework of the general field of argumentation set in the case. Frames used to introduce each micro topic of argumentation provide the discourse dynamics and allow to arrive to a well-reasoned, legally and linguistically clear conclusion.

The analysis of the material shows that one micro topic is typically disclosed in one or rarely two-three paragraphs that are rather big in terms of text volume.

The final part of the document, court decision itself, reasoned and agreed with all the judges sitting in the appeal, is very small in terms of text volume; in fact, it is a number of quite standardized and clichéd phrases: Accordingly, we affirm the court opinion of the district court.

It is worth mentioning that a judge in charge of opinion text writing is aware of the argumentation result he or she is to arrive at. Guided by legal logic of structuring the argumentation, judges instinctively choose frames as linguistic means of developing the discourse into the present direction. Analysing the texts of court opinions of the same category the authors identified a recognizable pattern of frames sequence. Though this pattern is far from being strict and is subject to variations depending on case circumstances and writing conventions of a particular court, still certain regularity of its repetition has been revealed through the analysed texts.

\section{Appellate ruling}

The argumentative part of an appellate ruling is commonly marked by the cliché phrase "the appeal court found" (graphically the last lexeme in the sequence is in bald, capitalized and placed on the separate line). It is important to point out that this word combination marks the beginning of the main argumentative part of the document, but not the court decision itself. Semantically the main part can be divided in to two parts: the first part states facts regarding the decision of the court of first instance and claims of both prosecutor and defendant. The second part provides detailed reasoning for the following appellate ruling.

The first part is typically introduced by the frame "Fact - classification of the fact". This frame sets the argumentation field through precising the focus fact in necessary and sufficient detail for the recipient to understand the starting points of the argumentation.

By the court sentence, $X X$ was found guilty and convicted of illegal possession without the purpose of selling a drug.

On the text level this frame may be realized in more than one paragraph depending on the complexity of the case. 
The analysed materials reveal that "Fact - classification of the fact" may be supported by the frame "Fact the presence / absence of the possibility of the existence of the fact".

The crime was committed under the circumstances detailed in the court sentence.

The main function of using this frame is to further precise the argumentation field through excluding from the discussion the aspect of circumstances related to case that have been thoroughly considered by the court of the first instance and are not to be reviewed.

The first part of the appeal ruling pivots on and is organized around the frame "Fact - limits of verification" which textually realises clearly and unambiguously formulated claim launched by the council for defence on behalf of the convicted. The position of the claimant is to be supported by reference to legal doctrines, principals and specific articles of the Criminal Code and Criminal Procedural Code of the Russian Federation.

In the appeal, lawyer XX in the interests of convicted XXX., expresses disagreement with the court sentence, asks to change it. In support of the arguments, referring to the norms of the Criminal Code of the Russian Federation, the Code of Criminal Procedure of the Russian Federation...

The main function of this frame is to clearly specify the argumentation field, it stipulates all the argumentation steps that will follow. The function of this frame in Russian appellate ruling is similar to that of the US Opinion, however there are considerable differences in their discourse realization.

First of all, there is difference in textual position of the frame "Fact - limits of verification": in Russian appellate ruling: it most commonly occurs after the frame "Fact - classification of the fact" towards the end of the first part of the document, while in US Opinion this frame usually occurs in the initial position opening the whole argumentative part of the opinion. In both types of the judicial discourse this frame is commonly supported by reference to various sources of law depending on the legal system which enhances the objective component of the proposed limits of the verification.

It is interesting to note that in appellate ruling texts the claim points that are sought to be satisfied or granted by the court are usually formulated on behalf of the lawyer for the benefit of the defendant ( the translation of the Russian text into English is provided $\mathrm{n}$ the word-to-word format):

In the appeal, lawyer XX in the interests of convicted $Y Y$, expresses disagreement with the court sentence, asks to change it.

[The lawyer] asks to apply with respect to the defendant the provisions of Art. 64 of the Criminal Code of the Russian Federation and reduce the amount of the imposed punishment...

In US opinion texts on the contrary the appeal points are formulated by the defendant him/herself and are introduces by strong performative verbs: the defendant contends, believes, considers...

Another specificity of the "Fact - limits of verification" frame's linguistic representation in appellate ruling texts lays in its function of further restricting the argumentation field by including the position of the public prosecutor, which is not typical for the opinion texts:

In objection to the appeal, public prosecutor XX asks to leave the sentence unchanged, and the lawyer's complaint, without satisfaction. 
Such complex textual representation of the "Fact - limits of verification" through featuring two counter positions apparently serves the purpose of justifying the set limits of the verification from the perspective of both parties to the procedure, as well as underlying the adversarial nature of the procedure.

The beginning of the second part is signalled by the following ritual phrase (meaning that the court having duly considered the materials of the criminal case comes to the following decision).

Having checked the materials of the criminal case, the appellate court makes the following decision.

On cognitive level the second macro topic is introduced by the frame "Fact - conditions for the fact's existence". The central "fact" which is in the focus of the whole document is the existence of the court's decision based on the analysis of the case materials. Ensuing argumentative steps are basically supportive to this focus fact.

The criminal case was considered in accordance with the requirements provided for by Art. 314 - 316 of the Code of Criminal Procedure of the Russian Federation.

The actions of the convicted person were qualified by the court under Part 1 of Article 228 of the Criminal Code of the Russian Federation as illegal possession of narcotic drugs in a significant amount without the purpose of selling.

The mental state of the convict was checked, he was recognized as sane.

The analysed material led authors to believe that such supportive arguments are typically, but not exclusively, realized through the use of "Fact - classification of the fact" frame. The most common argumentative strategy applied by authors of such type of judicial documents is to line up supportive facts in rigorous and objective manner.

The argumentation discourse dynamics may also be developed through the use of other frames as well, depending on author's intention and case particulars. For example, the use of "Fact - the presence / absence of the possibility of the existence of the fact" frame enables the author to streamline the discourse flow towards the intended conclusion, precluding other argumentative topics that are outside the set argumentative field from being raised.

The court compliance with the special procedure for the trial is not disputed in the lawyer's appeal.

The use of frame "Presentation of the fact - competence of the fact's source" also serves the purpose of strengthening the court's position on the correctness of the sentence handed down by the court of first instance.

Taking into account the specific circumstances of the case, the commission of a crime of small gravity, data on the personality of the convicted person, the court came to a reasonable conclusion about the imposition on $X X$ of punishment in the form of a fine, while sufficiently motivating the decision. At the same time, it is determined within the framework of the sanctions of Part 1 of Article 228 of the Criminal Code of the Russian Federation, in the minimum amount, in compliance with the requirements of Art. 46 of the Criminal Code of the Russian Federation, in proportion to the deed, and the personality of the convicted person. 
It should be noted however that the discourse function of the mentioned frame differs considerably in American and Russian argumentative judicial discourse. In court opinion texts the frame "Presentation of the fact - competence of the fact's source" frequently opens argumentative micro topics of which the main argumentative part of the document is composed, it is often used as part of the argumentative strategy of refuting the defendant's argument. In Appellate ruling texts this frame never occurs in the opening position of argumentative topics, it functions as a discourse unit that signals the intention of the author of the text to support the sentence of the first instance court.

The analysis also revealed that traditional drafting of Russian appellate ruling texts precludes the use of emotionally coloured lexical components, which depersonalizes the author of the text and highly contributes to achieving maximum objectivity of the reasoning. This is contrasted to US court opinion texts drafting, which also strives for objectivity, but still some emotionally coloured lexical components may be admitted to the text and may be regarded as a peculiarity of judge's idiostyle.

\section{RESULTS AND DISCUSSION}

The undertaken experiment convincingly demonstrated the applicability of the identified argumentative frames to the analysis of argumentative judicial discourse of different legal systems. The argumentative frames proposed by the authors function as meta-language for analysis of the judicial discourse dynamics, an instrument to trace and describe regular patters of frame distribution in the documents of similar function but drafted differently in compliance with traditions of their respective legal systems.

Regarding the US appeal court opinion affirming the decision of the court of the first instance, the most common pattern of argumentation frames' sequence can be presented as follows:

"Fact - limits of verification" most often opens the argumentative part of the opinion text; it sets rigid boundaries of what is going to be debated. This frame frequently, but not obligatory, is followed by "Fact conditions for fact's existence" or "Fact - competence of the fact's source" frames. Every new micro topic in the following text tends to be introduced with "Presentation of the fact - classification of the fact" frame; it should be mentioned that most frequently such micro topics are introducing from the defendant - appellant perspective i.e., through the use of reported arguments. Each of such frames identifies a new subtopic for judge's argumentation which is developed through the use of other frames. Schematically the proposed frames sequence pattern is presented below.

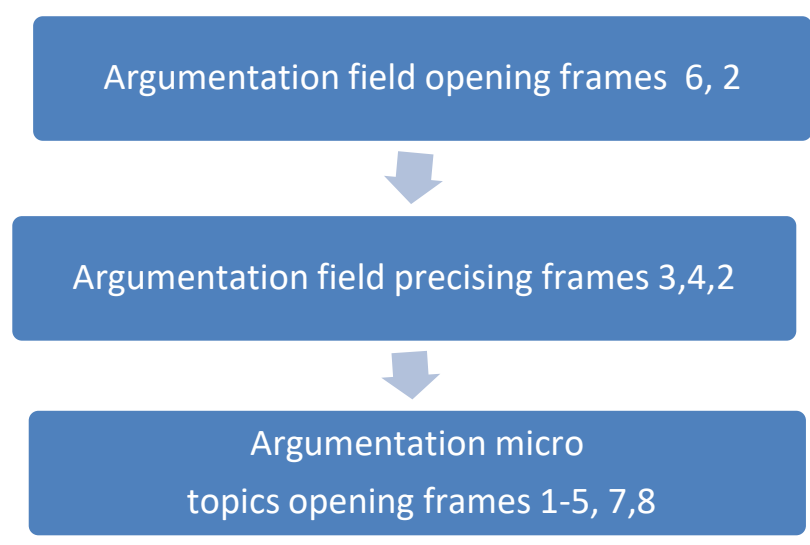

Figure 1. Frames sequence pattern in opinions. 
Appellate ruling texts have different semantic organization in comparison to opinion texts which fact necessarily entails different pattern of discourse frame sequence. The argumentative part of a typical appellate ruling text can be semantically divided into two sections according to their functions in argumentation: the first part sets the argumentation field through a series of steps; the second part develops the argumentation in line with the set goal.

The first part is most commonly introduced with the frame "Fact - classification of the fact", which leads the recipient in starting points of the decided case and thus sets the general argumentation field. This argumentation field is normally subject to further precision through the use of other frames that are supportive to the opening frame on the one hand and ensure the unfolding of the discourse dynamics leading to the "central" frame (frame: "Fact - limits of verification") which rigorously defines the limits of the general argumentation field. Such structuring of the argumentation dynamics pattern is not typical for US court opinion texts, where the writer prefers to set clear boundaries at the beginning of every argumentative macro topic.

The second part most commonly opens with the use of "Fact - conditions for the fact's existence" frame. Through the use of this frame the author of the document identifies the existence of the "focus" fact - the existence of a well-reasoned decision on the case. The main focus fact is supported by and developed through a sequence of other frames, which do not form a regular pattern, but among which frames "Fact classification of the fact", "Fact - competence of the fact's source", "Presentation of fact - competence of the fact's source" are most frequently used. It is interesting to observe that the argumentative discourse dynamics of Appellate rulings almost never uses the frame 7 " Fact - the statement of a goal" in its realization.

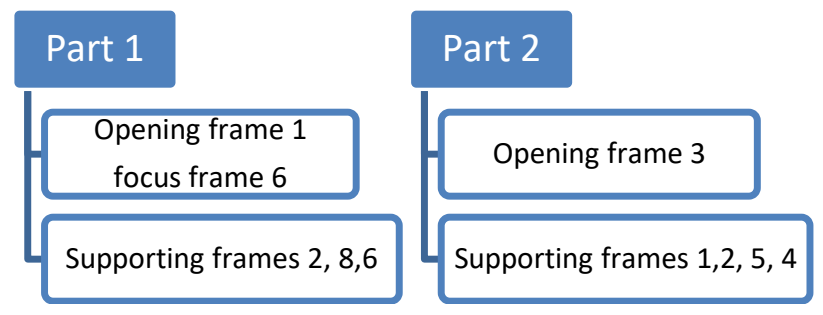

Figure 2. Frames' pattern in appellate rulings.

It should be noted once again that the identified argumentative frames patterns in both category of the analysed documents demonstrate certain regularity with insignificant variability of their occurrence. Taking into consideration the limitations on type of decision (affirming the decision of the lower court) and jurisdiction, it may be assumed that the identified patterns of the argumentation frames' distribution may be common and to certain extend traditional only to the analysed category of texts.

The authors were also interested to see if some frames prevailed in terms of frequency of their occurrence, for in the course of working with the material it appeared that some frames occurred more often than others. For this reason, the authors conducted quantitative analysis of the identified frames' occurrence in the corpus of the court opinion texts selected for analysis.

The diagram shows the percentage of argumentation frames occurrence in the corpus of analysed opinion texts. As can be clearly seen, there is quantitative difference in frames occurrence in the court opinion texts. Apparently this difference can be attributed to the fact that not all of the identified frames have equal argumentative potential for structuring and developing judge's argumentation. Frames that have capacity to occur on all of the three levels of above presented pattern scheme can be regarded as most universal in 
terms of structuring the argumentation on the one hand, on the other hand, creating in the joints of argumentation cognitive structure they ensure discourse dynamics, marking judge's strong position on what is going to be discussed further. In the respect of the above the analysed material revealed that frame 2 has strong argumentation potential, it can perform a wider range of discourse functions from setting the general field of argumentation to narrowing it down to a precise micro topic. Frames occurring on the lowest level of the suggested patterns have more limited application and perform more specific discourse functions.

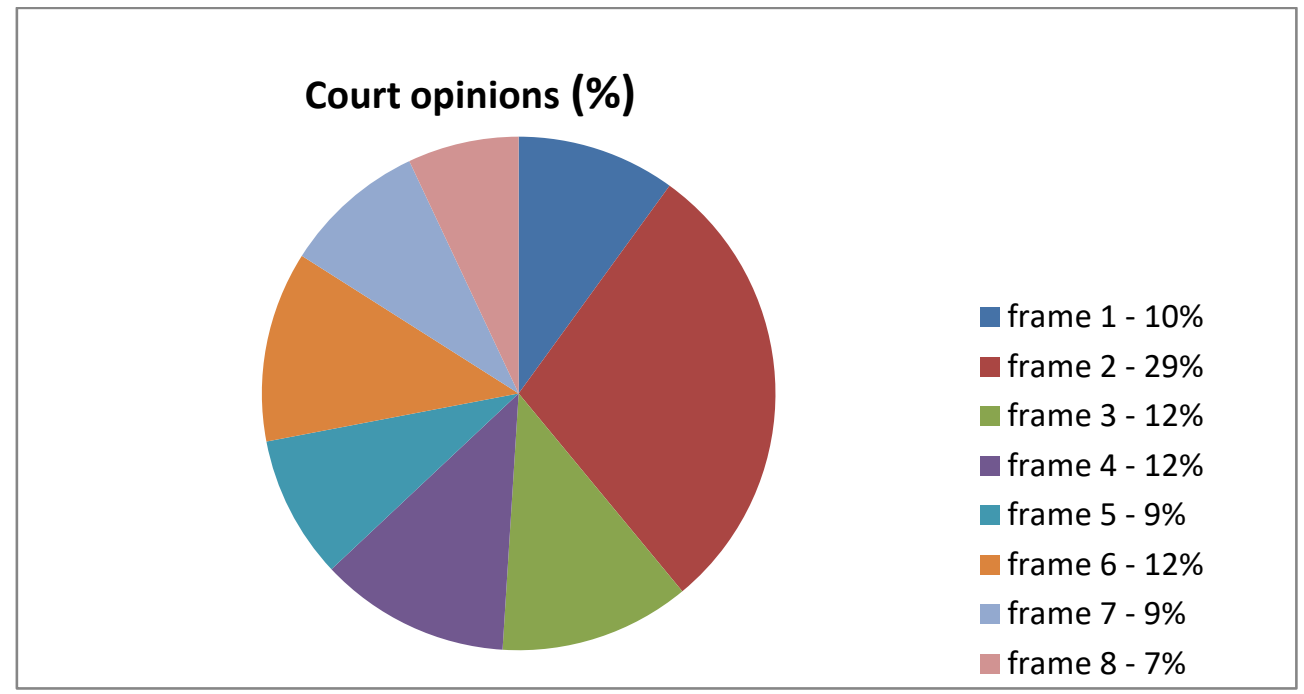

Figure 3. Percentage of frames occurring in the analysed corpus of opinion texts from total $100 \%$.

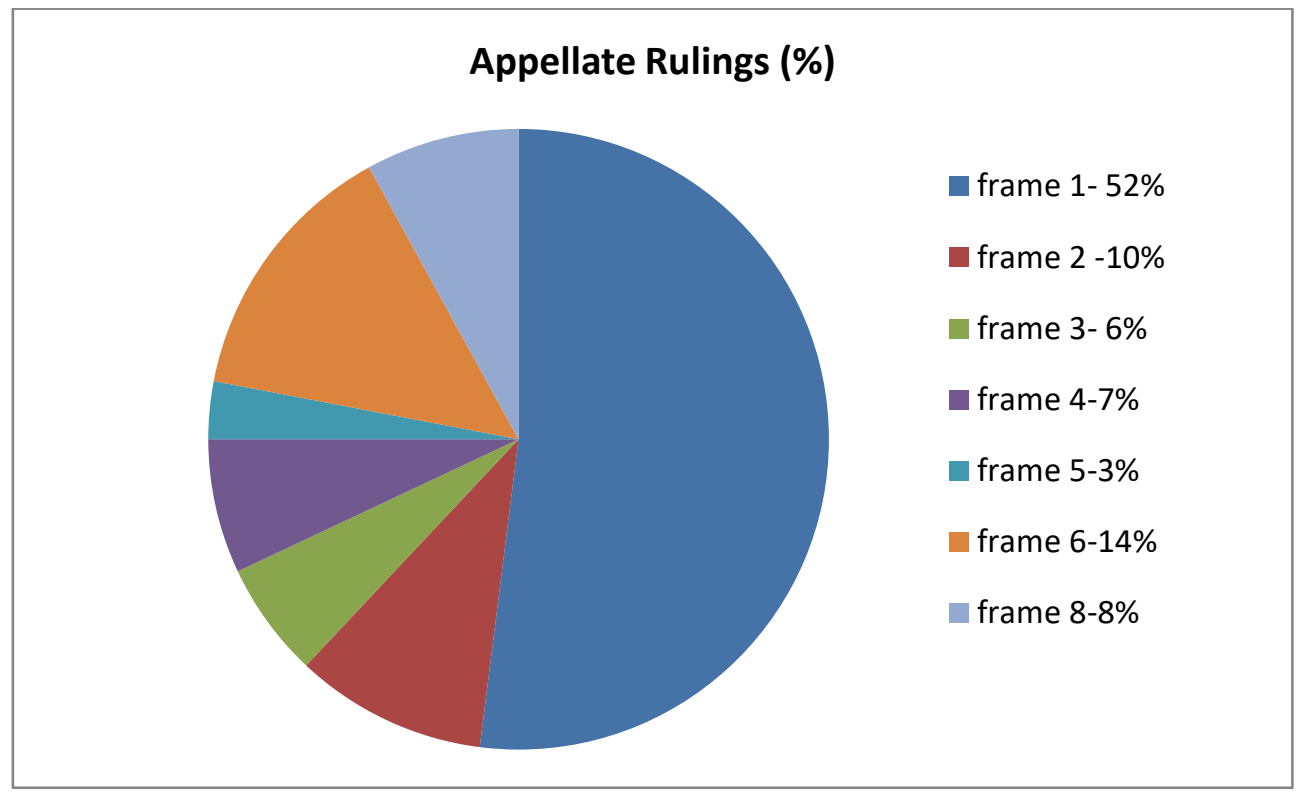

Figure 4. Percentage of frames occurring in the analysed corpus of appellate ruling texts from total $100 \%$.

As can be clearly seen from the diagram there are considerable discrepancies in terms of frequency of frames' occurrence in the argumentative discourse of analysed types of documents. Authors of Russian Appellate Ruling texts obviously prefer to structure the argumentation through the use of a concrete fact and 
its attribution to a particular legal category. Apparently this can be explained by the specificity of the legal system within which the document is drafted - in civil law system the key factor of a well-reasoned court decision is to relate the discussed legal matter under appeal to a correct article or its section(s) of the Criminal Code. From this perspective the frame "Fact - classification of the fact" has a very high argumentative potential in comparison to others and in comparison to the frequency of its use in US opinion texts. On the basis of the analyses, it can be concluded that though the same frames can be used as meta language to describe the development of the argumentative discourse dynamics, still their argumentative potential depends on the legal system within which the discourse unfolds. The research findings add new comparative data to previous information on the frame structure specifics of legal judgements in national legal systems and languages, including, for instance, Japanese (Yamada, Teufel \& Tokunaga, 2019), Brazilian (Losekan, Dias \& Camargo, 2020), English (Duke, Thom \& Gleeson, 2020) legal discourses.

Moreover, the results specify earlier findings with regard to the trends in conceptual macrostructure of international legal discourse on human rights (Atabekova \& Radich, 2020).

\section{CONCLUSION}

The empirical data obtained as the result of the experiment suggest the applicability of the identified argumentative frames as meta-language for describing argumentation dynamics in appeal court decisions pertaining to different law systems. It also revealed that within the scope of the analysed category of judicial texts it is possible to trace stable cognitive patterns of structuring the argumentation. The identified patterns are characterized by certain regularity of frames' occurrence in the joints of the argumentation cognitive structure; however, these patterns are not absolutely rigid and subject to certain variability. The undertaken research reveals that from cognitive perspective the judicial argumentative discourse of the appeal court decisions is organized in two basic levels: 1) setting the field of argumentation; 2) making the set argumentative field more precise narrowing it to particular issues; for US court opinions one more level of argumentative discourse organization is characteristic - 3) addressing each of the identified argumentation micro topics. At each level a particular set of frames operate ensuring the development of the discourse dynamics. However, some of the frames possess greater argumentative potential and can operate on more than one level. In terms of frames' frequency of occurrence in the texts of appeal court decisions it should be noted that judges perceive frames as having different argumentative potential, which is revealed through unequal frequency of their use in the text. Moreover, judges working within both analysed law systems differently perceive the argumentative potential of the same frames which results in different patterns of frames' distribution. However, the quantitative analysis revealed that frames containing the modus function "classification of fact" are most frequently used in the judicial discourse of both types of appeal court decisions. This fact leads the authors to believe that the discourse function "classification of fact" is characteristic to judicial discourse.

Taking into consideration that authors limited the analysis to the texts of specified category of cases within criminal law domain, it may be assumed that the identified regularities in structuring the argumentative discourse in affirming appeal court decisions may not be the same in other categories of cases within other legal domains, civil law, for example, or in reversing appeal court decisions. This fact opens perspectives for further research into comparative analysis of cognitive structuring of the judicial argumentation in court decisions pertaining to various jurisdictions and decision types. 


\section{REFERENCES}

Atabekova, A. \& Radic, N. (2020). EU legislative discourse on unaccompanied minors: Exploring conceptual-linguistic architecture. Journal of Legal, Ethical and Regulatory Issues, 23(1), 1-9. Retrieved from: https://www.abacademies.org/articles/EU-legislative-discourse-on-unaccompaniedminors-exploring-conceptual-linguistic-architecture-1544-0044-23-1-460.pdf

Atabekova, A. \& Shoustikova, T. (2018). Language issues within forced migration at borders and temporary settlements: An integrated content analysis. European Research Studies Journal, 21, 690-700.

Atabekova, A.A., Gorbatenko, R.G., Shoustikova, T.V. \& Radić, N. (2019). Language analysis of convention on the rights of the child to enhance societal awareness on the issues. Journal of Social Studies Education Research, 10(4), 506-529.

Avdeev, V.A., Avdeeva, O.A., Shagieva, R.V., Smirnova, V.V., Mashkin, N.A. \& Taradonov, S.V. (2019). The mechanism of legal regulation in the conditions of globalization and formation of information environment. Regional aspect. Journal of Environmental Management and Tourism, 10(7), 1517152.

Bayanova, A.R., Vodenko, K.V., Sizova, Zh.M., Chistyakov, A.A., Prokopiev, A.I. \& Vasbieva, D.G. (2019). A philosophical view of organizational culture in contemporary universities. European Journal of Science and Theology, 15(3), 121-131.

Bhatia, V.K. (1998). Analysing Genre: Language Use in Professional Setting. New York: Longman.

Björling, E. (2016). The Expression of Legal argumentation: Towards a Methodology for Narrative Studies of "Discourses of Subsumption". International Journal of Legal Discourse, 1(1), 117-132. https://doi.org/10.1515/iild-2016-0003

Bubnova, I.S., Khvatova, M.A., Chernik, V.E., Popova, O.V., Prokopyev, A.I., Naumov, P.Yu. \& Babarykin, O.V. (2018). Research of Professional Activity Features of Ecologist at Carrying Out Public Ecological Examination. Ekoloji, 106, 999-1006, Article No: e106183.

Carlson, K., Livermore, M.A. \& Rockmore, D. (2016). A Quantitative Analysis of Writing Style on the U.S. Supreme Court, 93, 1461-1476. https://doi.org/10.2139/ssrn.2554516

Chilingaryan, K. \& Lutkovskaya, L. (2015). Frame-analysis of Argumentation in Court Opinion Texts: Empirical Research. Educational research and reviews, 10(21), 2834-2840. https://doi.org/10.5897/ERR2015.2464

Dijk T.A. van (1997). Discourse as structure and Process. New York: Sage Publications.

Dijk, T.A. van (2006). Discourse, Context and Cognition. Discourse Studies, 8(1), 159-177. https://doi.org/10.1177/1461445606059565

Duke, K., Thom, B. \& Gleeson, H. (2020). Framing 'drug prevention'for young people in contact with the criminal justice system in England: views from practitioners in the field. Journal of Youth Studies, 23(4), 511-529. https://doi.org/10.1080/13676261.2019.1632818

Feteris, E.T. \& Kloosterhuis, H. (2009). The Analysis and Evaluation of Legal Argumentation: Approaches from Legal Theory and Argumentation Theory. Studies in Logic, Grammar and Rhetoric, 16(29), 307331.

Feteris, E.T. (2017). Fundamentals of legal argumentation. A Survey of Theories on the justification of Judicial decisions. Amsterdam: Springer. https://doi.org/10.1007/978-94-024-1129-4

Fillmore, Ch.J. (1977). Scenes-and-frames Semantics.Amsterdam: North-Holland.

Gordon, T.F. (1994). The Pleadings Game: an exercise in computational dialectics. Artif. Intell. Law, 2(4), 239-292. https://doi.org/10.1007/BF00871972

Hinkle, R. \& Nelson, M. (2017). The Importance of Being Caustic: The Linguistic Features of Influential Dissents. Retrieved from: http://minelson.org/papers/HinkleNelsonDissent.pdf 
Khairullina, E.R., Shubovich, M.M., Bogdanova, V.I., Slepneva, E.V., Mashkin, N.A. \& Rodyukova, T.N. (2020). Modern student youth civic identity: Political activity or social responsibility? Opcion, 36(Special Edition 27), 1703-1717.

Losekan, C., Dias, T.H. \& Camargo, A.V.M. (2020). The Rio Doce mining disaster: Legal framing in the Brazilian justice system. The Extractive Industries and Society, 7(1), 199-208. https://doi.org/10.1016/j.exis.2019.11.015

Luoi, R.P. (1998). Process and Policy: Resource-Bounded NonDemonstrative Reasoning. Computational Intelligence, 14(1), 1-38. https://doi.org/10.1111/0824-7935.00055

Prakken, H. (2002). Incomplete arguments in legal discourse: a case study. In JURIX 2002: The Fifteenth Annual Conference on Legal Knowledge and Information Systems. Amsterdam: IOS Press.

Prokofieva, E.N., Erdyneyeva, K.G., Galushkin, A.A., Prokopyev, A.I., Prasolov, V.I., Ashmarina, S.I., Ilkevich B. \& Kubiatko, M. (2018). Risk based ecological economics to engineering students. Eurasia Journal of Mathematics, Science and Technology Education, 14(3), 753-764. https://doi.org/10.12973/ejmste/80903

Szczyrbak, M. (2009). Genre-based Analysis of the Realisation of Concession in Judicial Discourse. Jagiellonian University Press, 126, 128-148. https://doi.org/10.2478/v10148-010-0011-z

Szczyrbak, M. (2014). Stance taking Strategies in Judicial Discourse: Evidence from US Supreme Court Opinions. Studia Linguistica Universitatis lagellonicae Cracoviensis, 131(2014), 91-120.

Tannen, D. (1993). Framing in discourse. Oxford: Oxford University Press.

Toulmin, S.E. (2003). The uses of argument. Cambridge: Cambridge University Press. 2nd edition. https://doi.org/10.1017/CB09780511840005

Ungerer, F. \& Schmidt, H.-J. (1996). An introduction to cognitive linguistic. New York: Longman.

Yamada, H., Teufel, S. \& Tokunaga, T. (2019). Building a corpus of legal argumentation in Japanese judgement documents: towards structure-based summarisation. Artificial Intelligence and Law, 27(2), 141-170. https://doi.org/10.1007/s10506-019-09242-3

\section{@) $\Theta \Theta \Theta$}

This work is licensed under a Attribution-NonCommercial-NoDerivatives 4.0 International (CC BY-NC-ND 4.0). 